conscious. Valve of tube to gas-stove turned on. Symptoms : Coma, stertorous respiration, cyanosis, contracted pupils, strong odor of gas in breath. Kneejerk absent. From thighs up, cutaneous sensation seemed unimpaired. Urine : smoky ; acid; trace albumen; vermilion color at line between nitric acid and urine; no odor of gas. 'Treatment: Oxygen at entrance; brandy, ether, carbonate of ammonia, and atropia subcutaneously. A few hours later patient opened his eyes, and pupils reacted to light, right more than left. Could swallow milk and brandy. Slight convulsions ensued, the spasms recurring of tener and oftener. Respiration stopped, and was started again by faradic battery. In the evening, pulse imperceptible; temperature $104^{\circ}$; respiration $60 . \mathrm{Pa}$. tient died on the second day.

Autopsy records : Acute pneumonia and bronchitis ; chronic hydronephosis (Dr. Draper).

Casie XXVII. September 20, 1890. Female, age thirty-five, from Nova Scotia. 'Two nights before entrance had blown out gas, and was found unconscions the next morning. 'Twelve hours' exposure. Symptoms : Coma, cyanosis. Respiration rapid and shallow, 30 ; pulse 100 ; temperature $101^{\circ}$. Urine: 1,033 , trace of albumen, hyaline, and fine granular casts. The day after entrance convulsions began, first of arms, with closed fists and thumbs turned in ; then increasing to opisthotonos. They occurred every three or four minutes, and lasted thirty seconds or more. 'Treatment: Nutritive euemata, rectal injections of chloral and bromide, oxygen inhalations frequently. On the third day she answered questions, swallowed easily ; no cyanosis; pulse full and regular. Convulsions had ceased. But patient became weaker ; coma returued; and she died after six days.

No autopsy.

CAsE XXVIII. November 27, 1890. Boston Hotel. Female. Blew out gas. Found unconscious in moruing. Man dead in same room. Symptoms: Coma, cyanosis, stertor. Treatment: Oxygen, stimulants, lieaters. No response. Died day after entrance.

No autopsy.

Case XXIX. March 6, 1892. Male. Said to have morphine habit. Bottle half full of morphine brought with him. Found in room with gas turned on. Symptoms: Coma ; pulse 112, weak; respiration 44 ; fine, moist râles at base of lungs. Urine : 1,020 , slight trace of albumen, blood, and renal epithelium, no casts. 'Treatment: Oxygen frequently, black coffee, atropia. Died in ten hours.

No autopsy.

Case XXX. April 20, 1892. Male. Brought in unconscious by police, after twelve hours' exposure to gas. Skin warm and moist. Moved arms and legs. The next day more comatose; slight convulsions; free perspiration ; pulse weaker. Oxygen every half hour. Swallowed a few drachms of milk and brandy. Failed rapidly, and died during the night. Duration two days.

No autopsy.

The White House Quaran'tined. Placards announcing that scarlet fever is within have been placed on the White House in Washington. In order that this disease may not be included among the inheritances to the vext administration, the building will be thoroughly cleaned before the arrival of Ruth Cleveland.

\section{FURTHER NOTES ON REMOVAL OF THE STAPES.}

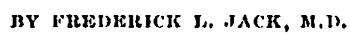

At the last meeting of the American Otological Society, July 20, 1892, I presented for consideration a new method of treatment for the relief of symptoms attending adhesive inflammations of the middle ear. This method, the removal of the stapes, was described, and sixteen cases were reported as the beginning of a series of original investigations. 'The results gave reason to hope that a means of relief in many cases was on the verge of realization. Aural surgery, as is well known, had by degrees been advancing in the direction of the oval window, and there was a growing belief that an open fenestra ovalis would very greatly improve the power of hearing.

Among those who have published their investigations in this direction are these: Kessel, in 1875, first performed circumcision of the stapes, with improvement. In 1876 Michel $^{1}$ perforated the drum, and exerted pressure upon the stapes with a sound, improvement in hearing following. In 1888 this operation was revived by Boncheron and Miot. ${ }^{2}$ 'Tenotomy of the stapedius muscle was first performed by Kessel, ${ }^{8}$ and later by Urbantschitsch, ${ }^{4}$ who out of three cases got improvement in two. Cases of exfoliation of the stapes with improved hearing have been reported by Berthold. ${ }^{6}$ He ascribed the gain to the closing artificially of a perforation in the drum. Also cases by 'Trültsch, ${ }^{\circ}$ by Buck,' by Bock, ${ }^{8}$ and two cases by Schwartze. ${ }^{\circ}$ One cuse of accidental removal, with improvement in hearing, by Botey. ${ }^{10} \mathrm{He}$ also re. moved the stapes from animals safely and thereby improved their hearing.

The practicability of this procedure on the human subject has now been fully demonstrated by several observers and its value in some cases clearly proven. No clain is male that it will help all cases, but it surely does some. My object in this paper is to give the results of further observations and experience with the operation, especially as to its technique, and its application to the different forms of middle-ear disease; also to record the permanency of the good results in most of the original sixteen cases.

In general, the operation previously described is employed. ${ }^{11}$ 'There are a few details, however, worthy of brief notice. The shape of the incised piece of membrane is immaterial, but it is important to carry the posterior and upper cut as close to the auditory ring as possible, for in not a few cases the joint is on a line with this ring or situated a little above it. Usually, after any incision except a straight one, the membrane curls away from the elge of the wound. Cases will undoubtedly occur where, from bony ankylosis, or from a high position of the oval window, or what is practically the same thing, a prominent auditory ring, removal of the ossicle is rendered more difficult. At times it is impossible to remove the bone eutire. Where the head of the bone is high up, the

1 Zoitschrift flir med. Wiss., 1876, No. 42.

2 Bullot. med. do J'uris, 18*8, p. 653 .

3 Archiv für Ohrenheilkundo, vol. ii, p. 109.

4 Wien. med. Pr., 1877, vol. xviii - xxi.

G Zeitsohrift fitir Ohrenhoilikundo, vol. $x i x, p .1$.

"Archiv fir Ohronoilkunde, vol. iv, p. 100.

? Manunl of Disenses of the, Ear.

Aroliv fitir Olirenhellkunde, vol. vili, p. 228.

A Archiv fír Ohronhetlkunde,

Archiv fir Ohronhiolk unde.

10 Jxperionoes d'avilsioll de l'étrier chez
malndies de l'oroillo, No. 1, January, 1891.

malades de l'oroillo, No. 1, January, 1891. 
operator must by careful manipulation pass the hook between the crura. 'The sense of the feeling can bo ret the only guide, since the bone is beyond the range of sight. $\Lambda$ case recently operated on best illustrates this point, and also one other point, namely, the importance of a differential diagnosis :

Miss C., thirty years old, complained of progressive deafness of many years standing in both ears. The left membrana tympaui was very much thickened and retracted, manubrium decidedly foreshortened, leaving a much-contracted field for operating. The usual small triangular opening in the drum was made. 'The incudo-stapedial joint could only be made out when the assistant held the patient's head considerably to one side. The operation was performed in the usual way up to the point of extraction of the stapes. This step was made entirely in the dark, on account of the high position of the oval niche. The ossicle was quickly found and removed, with so little resis. tance however as to lead to the belief that it could have offered little obstacle to the sound waves and that therefore the hearing appuratus beyond in the vestibule was the real seat of the trouble. This condition was strongly suggested by the tests made before the operation, and it was confirmed afterwards by the same meaus. 'There was no dizziness, and the patient, as frequently happens, was up and about on the next day.

In all cases the ear should bo rendered aseptic by syringing with a mild antiseptic fluid some time before the operation, in order to avoid congestion of the tissues, because in such a condition the parts are not well defined. It is seldom necessary to cut or injure the mucous membrane. Care should be taken to thoroughly perform each step, and to render the field of operation perfectly free from hamorrhage by the use of a sterilized four per cent. solution of cocaine. In one case in which instruments dipped in uinetyfive per cent. alcohol were used, a sharp inflammation followed the operation. 'That this was due to the irritating influence of the alcohol is a fair supposition, from the fact that in the operations before and after, in which a solution of carbolic acid (1 to 60) was always used for the instruments, no inflammatory reaction has occurred.

As regards the application of the operation to the different classes of ear disease. In cases of otitis media suppurativa, after the otorrhoca has ceased the incudostapedial joint is firmly fixed by bands of adhesion. Briefly described, this condition of the bone offers a mechanical hindrance to the transmission of sound waves to the vestibule. Relieving this obstruction by removal of the stirrup is found to increase the hearing power for the voice very materially.

Another set of cases is very similar pathologically, otitis catarrhalis adhasiva. 'There is proliferation of tissues with ankylosis of the ossicular chain. Here again good results by removal of the bone have been demonstrated.

'There is a third class, otitis media insidiosa (sclerosis), in which it is generally believed that the ankylosis is not fibrous but osseous. This condition is usually characterized by a high degree of deafiness and tinuitus. Appearances of the tympanum are either normal or nearly so. Judging from a few experiences with this troublesome condition, the region of the foot-plate would uppear to be the principal seat of the bony ankylosis. I can only say in evidence of this that in some of these cases the foot-plate, in part or whole, remained behind after the removal of the head and crura, an accident which at present is unavoidable and insurmountable. As might be expected the improvement in hearing is not as great as in other cases. Larger experience with this class of cases may, however, give better results.

It seems hardly necessary to say that diseases of the internal ear are not affected by this operation. It must be carefully determined beforehand therefore in each case by special tests whether the impairment of hearing is due in part or whole to changes in the labyrinth.

It is now six months since the first cases were operated upon, long enough to form some idea as to the permanency of the results. Most of these cases have been again tested within a week, by Dr. William S. Bryant and myself, aided by Dr. Crockett, houseofficer. The ears, without a single exception, have remained healed ; the wound in the drum in most cases was found cicatrized, thereby restoring the natural protection to the middle ear.

The influence of the operation on tinnitus aurium, judged by these cases, is very uncertain. Some, in whom it existed previous to the operation, have been free from this trouble since. On the other hand, the reverse is true in a few cases where a slight noise is now noticed at times.

A matter of considerable interest is the effect of removal on the labyrinth. Theoretically, there should be a grand general disturbance; practically, this is not the case. The symptom, vertigo, was closely searched for, but was found in one case only, that of a woman forty-seven years of age. Dizziness was, however, an old complaint with her, and was very likely due to dyspepsia. She volunteered the information that the trouble was less frequent of late than for a short time after the operation. In a few cases vertigo, which was complained of before the operation, has entirely disappeared.

'The improvement noted in hearing the tuning-fork, both by air and bone, was found essentially the same as when tested six months ago.

'The test by König's rods showed in one case a slight gain of 5,000 vibrations per second; in another, the loss of the same. In one case the considerable gain of 15,000 vibrations after the operation was still held.

The hearing for the watch indicated in some cases a slight gain, in others, a slight loss. In cases of slight loss for the watch and rods, this of course indicating a diminished perception for high tones, the hearing power for the voice was apparently increased. This peculiarity in the relation between hearing the voice and high tones is frequently found annong deaf people.

We now come to the point of most importance, to the patient at least, namely, a report of the hearing power for the voice. It is impossible at present to apply tests for this with anything like scientific accuracy. 'This is especially true in cases where the hearing is good in one ear and bad in the other. In these cases the ear on the other side was tightly stopped with cotton and the finger of an assistunt pressed tightly into the meatus. In those cases where the oval window was completely cleared, the change, if any, was a slight increase of hearing since that immediately following the operation. There was one 
exception. On the other hand, where the foot-plate remained, there was practically no change from preceding tests. In one case of removal from both ears the hearing remained perfectly good for five months, and was then somewhat dulled after a head cold, which closed the Eustachian tubes and caused marked retraction of the membrane. After inflation of both middle ears through the catheter the hearing was restored in one and partially so in the other. This would seem to show that the cicatrix over the oval niche was driven into the window by the closing of the tubes, and acted as an obstruction. It is proposed to remove, under cocaine, a piece of membrane from one side, with the object of contracting the cicatri. cial drum. By this it is hoped to counteract the tendency of the cicatricial membrane to sink into the fenestra.

In conclusion, I wish to emphasize the importance of a careful differential diagnosis in each case before advising the operation.

\section{Elinical gDepartment.}

\section{SOLID TUMOR OF OVARY.}

HY ,J. COLLINS WARHEN, M.D.

Sol.in tumors of the ovary are said to be exceedingly rare. According to Greig Smith, "Of all tumors of the ovary probably not more than three per cent. are solid; most of them are malignant sarcoma or cancer; true myoma has been found; pure fibroma is almost unknown."

The following case seems, therefore, worthy to be placed on record :

J. R., domestic, single, forty-three years of age, entered the hospital November 2, 1892. For the last twelve years she has suffered from epileptic seizures, which she describes as "giving warning," and affecting the right side mainly. Her general health has otherwise been good. There is no history of any injury to her head. Her mental condition is slightly below par. Catamenia have been regular, but ceased two months ago. She first noticed some soreness of the abdomen on bending over about four months ago, but not until two months ago did she notice any enlargement. She has not had any pain, but has experienced a feeling of weight and dragging when walking about.

The patient is poorly nourished, and there is a slight suggestion of cachexia in the face. On examination, the abdomen was found to be somewhat distended with ascitic fluid, and a large, very hard, and nodulated tumor was felt extending three inches above umbilicus and down to the pubes. It was quite movable and could be pusherl readily from side to side in the ascitic fluid.

On vagiual examination the uterus was found to be small, movable, and not connected with the growth. 'The hymen was well developed. The lungs and kid. neys were normal. There was a slight presystolic murmur, but the heart's action was otherwise good. The tumor was regarded as probably of a maliguant uature and possibly attached to the omentum. It was, however, thought advisable to perform an exploratory operation.

Laparotomy was accordingly performed on November 11 th. An incision was made below the umbilicus, about four inches in length, which disclosed a hard nodular mass of an opaque whitish color floating in ascitic fluid, about two quarts of which escaped. 'The incision was enlarged by the scissors to two inches above the umbilicus and with some manipulation the tumor was brought out through the wound, and was found to be attached to the left broad ligument. The pedicle was long and thin and was easily tied with a Staffordshire knot. The tumor on removal was found to be about the size of an adult head and to woigh eight and one-half pounds. An examination of the other ovary ehowed it to be about twice its normal size and hard and nodular, resembling somewhat in this respect the diseased ovary.

The patient made a good recovery, the temperature not rising above $100^{\circ} \mathrm{F}$, although the evening of the operation she sat up in bed and had several epileptic seizures during her convalescence. The stitches were removed on the thirteenth day, the union being perfect. The catamenia appeared on November $28 \mathrm{th}$, immediately after one of the seizures. Having been satisfactorily fitted with an abdominal belt, which I apply to all cases of laparotomy, she was discharged December 6 th in excellent condition.

The following is the report of the microscopical examination of the tumor by Dr. W. F. Whitney: "A large lobulated growth (size of the head), firm, not covered by peritoneum and united to a fragment of the Fallopian tube. Microscopic examination showed it to be made up of fibrous tissue, with here and there a few bundles of unstriped muscular fibre. Fibro-myoma." 'There were no cysts in any part of the tumor.

\section{A REMARKABLE DEFORMI'TY OF THE PELVIS, IN CONSEQUENCE OF FRACTURE OF THE SACRUM.}

HY BAR'TON COOKK HIRE', M.L., PHHADELPHA.

A wonan brought in to the gynecological ward of the Philadelphia Hospital, on December $16 \mathrm{th}$, gave the following history:

Age thirty-two. Has had six children, the last, three years ago. Three months ago, during a menstrual period, she fell from a third-story window striking with an unbroken fall upon the brick pavement of the yard below. One leg was broken, the skull, she thinks, was fractured, and some injury, she believes, was inflicted on the backbone. Since the fall she has not menstruated, and has suffered severe pain in the lower abdomen, which, however, of late has steadily decreased. She was transferred to our department from the surgical ward after her head injury and the broken leg had been repaired. An examination of the pelvis gave the following result: 'The uterus is in good position, movable; behind and to the right is a mass that gives me the impression of a diminishing, encysted hamatocele. Directly the finger enter's the vagina, a peculiarity of the posterior pelvic wall attracts attention. 'The coccyx and lower sacrum are much higher than they should be in the pelvic cavity, and they project forward at a right angle to the rest of the sacral bone, so that they encronch, to an extraordinury degree, upon the anteroposterior diameter of the pelvis. An external examination shows a transverse fracture of the sacrum at the level of the posterior inferior spinous processes of the iliac bones, a dislocation of the lower fragment inward, and a firm bony union of the two fragments at a right angle. From the seat of fracture to the tip 